\title{
The Sequence of Appearance of Leghaemoglobin and Nitrogenase Components I and II in Root Nodules of Pisum sativum
}

\author{
By T. BISSELING, * A. A. MOEN, R. C. VAN DEN BOS \\ AND A. VAN KAMMEN \\ Department of Molecular Biology, Agricultural University, De Dreijen 11, \\ 6703 BC Wageningen, The Netherlands
}

(Received 21 August 1979; revised 23 November 1979)

The sequence of appearance of nitrogenase components I and II and leghaemoglobin in root nodules of pea plants inoculated with Rhizobium leguminosarum (strain PRE) was studied using radioimmunoassays. Leghaemoglobin was detected before nitrogenase activity. The MoFe component (I) of nitrogenase was detected at the same time as leghaemoglobin, while the Fe component (II) of nitrogenase and nitrogenase activity appeared 1 and $2 \mathrm{~d}$ later, respectively. The same order of appearance of nitrogenase activity and leghaemoglobin was found in root nodules of cowpea plants inoculated with Rhizobium sp. $32 \mathrm{H} 1$.

\section{INTRODUCTION}

In an earlier paper (Bisseling et al., 1979) we demonstrated that leghaemoglobin in pea root nodules induced by Rhizobium leguminosarum was synthesized before nitrogenase activity could be measured. We also found that in the early phase of the development of nitrogen-fixing activity, the synthesis of the MoFe component (CI) of nitrogenase exceeded the synthesis of the Fe component (CII) (Bisseling et al., 1979). In this paper we report further experiments on the order of synthesis of leghaemoglobin and CI and CII of nitrogenase, which are three essential components for nitrogen fixation in pea-rhizobium symbiosis. A radioimmunoassay has been developed to quantify leghaemoglobin and $\mathrm{CI}$ and CII. This method is a few orders of magnitude more sensitive than the Mancini immunodiffusion assay (Mancini et al., 1965), which we used previously for the determination of leghaemoglobin; it has allowed us to extend the measurements towards the beginning of nodule development and to confirm that leghaemoglobin is present before nitrogenase activity is measurable. Moreover, we have now found that $\mathrm{CI}$ is synthesized before the presence of CII can be demonstrated in bacteroid extracts.

Fast- and slow-growing rhizobia differ in many respects (e.g. Paau, 1978). To investigate whether slow-growing rhizobium bacteroids differ from the fast-growing rhizobia $(R$. leguminosarum) in the order of appearance of nitrogenase activity and leghaemoglobin synthesis, we have studied the appearance of leghaemoglobin and nitrogenase activity in root nodules of cowpea plants inoculated with Rhizobium sp. $32 \mathrm{H} 1$. The results were similar to those obtained with the pea root nodules.

\section{METHODS}

Growth of plants. Pea plants (Pisum sativum var. Rondo) were cultured and nodulated with Rhizobium leguminosarum (strain PRE), as described earlier (Bisseling et al., 1978), at 19 to $20^{\circ} \mathrm{C}$ with an $8 \mathrm{~h}$ dark and $16 \mathrm{~h}$ light period. Rhizobium leguminosarum was cultured in a yeast/mannitol medium (Bisseling et al., 1978). Vigna unguiculata Walp (Blackeye Early Ramshorn) was cultured and nodulated with Rhizobium sp. 32H1, essentially under the same conditions as for the pea plants, but at $25^{\circ} \mathrm{C}$. 
Assay of nitrogenase. Nitrogenase activity of intact nodules was measured by the acetylene reduction method on pieces of the main root carrying the root nodules. Ethylene concentrations were measured in a Pye 104 gas chromatograph with a Porapak R column (Bisseling et al., 1978).

Preparation of bacteroid and plant proteins. The isolation of bacteroids and the preparation of soluble bacteroid proteins and plant proteins from root nodules were performed as described before (Bisseling et al., 1979). All manipulations were performed under anaerobic conditions in the presence of argon to prevent precipitation of nitrogenase. Root proteins from uninoculated plants were prepared from pieces of the main root in a similar way to soluble plant nodule proteins.

Preparation of antisera. Specific antisera against CI and CII of $R$. leguminosarum nitrogenase were prepared by injecting rabbits intravenously with $0.5 \mathrm{mg}$ of electrophoretically pure CI or CII (Bisseling et al., 1978) in $0.9 \%(\mathrm{w} / \mathrm{v}) \mathrm{NaCl} ; 1$ month later this was followed by a subcutaneous injection of $2 \mathrm{mg} \mathrm{CI}$ or CII in $0.9 \% \mathrm{NaCl}$, mixed with an equal volume of Freund's complete adjuvant (Difco). The rabbits were bled through the jugular ear vein $7 \mathrm{~d}$ after the second injection. Under these conditions the titres allowing immunoprecipitation with $1 \mathrm{mg} \mathrm{CI}$ or CII ml $\mathrm{ml}^{-1}$ in an Ouchterlony double diffusion assay were $1 / 64$ and $1 / 32$, respectively. Pre-immune serum showed no reaction.

Antiserum against leghaemoglobin from pea plants was raised in a rabbit as described previously (Bisseling et al., 1979). Antiserum against leghaemoglobin from cowpea plants was prepared in a goat and was a generous gift from Dr W. J. Broughton (Broughton et al., 1978).

Iodination of antigens. Electrophoretically pure CI, CII and the leghaemoglobins were each iodinated with $\mathrm{Na}^{125} \mathrm{I}$ (The Radiochemical Centre, Amersham). Protein $(5 \mu \mathrm{g})$ in $20 \mu 10.25 \mathrm{M}$-phosphate buffer, $\mathrm{pH} 7 \cdot 5$, was labelled with $1 \mathrm{mCi}(37 \mathrm{MBq})$ of $\mathrm{Na}^{125} \mathrm{I}(10 \mu \mathrm{l})$ by the addition of $30 \mu \mathrm{g}$ chloramine-T in $10 \mu \mathrm{l} 0.05 \mathrm{M}-$ phosphate buffer, $\mathrm{pH} 7.5$. The reaction was stopped by the addition of $400 \mu \mathrm{g} \mathrm{Na}_{2} \mathrm{~S}_{2} \mathrm{O}_{5}$ in $10 \mu 10.05 \mathrm{M}-$ phosphate buffer and $1 \mathrm{ml} 0.05 \mathrm{M}$-phosphate buffer, pH 7.5, containing $2 \mathrm{mg}$ bovine serum albumin. lodinated protein was separated from unreacted iodine by dialysis for $16 \mathrm{~h}$ against $510.05 \mathrm{M}$-phosphate buffer, $\mathrm{pH} 7 \cdot 5$, containing $0 \cdot 85 \%(\mathrm{w} / \mathrm{v}) \mathrm{NaCl}$. The specific radioactivity of the proteins was about $10^{7} \mathrm{c} . \mathrm{p} . \mathrm{m}$. $(\mu \mathrm{g} \text { protein })^{-1}$.

Radioimmunoassays. Radioimmunoassays against CI, CII and the leghaemoglobins were performed essentially as described by Hunter (1967). Iodinated protein ( $20 \mathrm{ng}$ ) and $1 \mu \mathrm{l}$ of CI, CII or pea leghaemoglobin antiserum or $0.1 \mu \mathrm{l}$ of cowpea leghaemoglobin antiserum was used in each assay. The final volume was made up to $1 \mathrm{ml}$ with RIA buffer [0.05 M-phosphate $\mathrm{pH} 7.5$, containing $0.85 \%(\mathrm{w} / \mathrm{v}) \mathrm{NaCl}, 0.2 \%(\mathrm{w} / \mathrm{v})$ bovine serum albumin, $0.01 \%(\mathrm{w} / \mathrm{v})$ thimerosal, $1 \%(\mathrm{v} / \mathrm{v})$ Triton $\mathrm{X}-100$ and $0.1 \%(\mathrm{w} / \mathrm{v})$ sodium deoxycholate] and the assay mixture was incubated overnight at $4{ }^{\circ} \mathrm{C}$. Complexes of $\mathrm{CI}$, CII or leghaemoglobin with antibodies were separated from the unbound molecules by precipitation with Protein A-Sepharose CL-4B (Pharmacia). The precipitate after centrifugation $(1 \mathrm{~min}, 10000 \mathrm{~g})$ was washed three times with RIA buffer. It was then suspended in RIA buffer and radioactivity was quantified with Hydroluma (Lumac, Basel, Switzerland) in a liquid scintillation spectrometer (Packard 2450).

\section{RESULTS}

\section{Characteristics of the radioimmunoassays}

The inhibition of binding of ${ }^{125}$-labelled $\mathrm{CI}$ by non-radioactive $\mathrm{CI}$ is shown in Fig. 1 . The lowest amount of $\mathrm{CI}$ that could be detected with this radioimmunoassay was $20 \mathrm{ng}$. The lowest amounts of CII, pea leghaemoglobin and cowpea leghaemoglobin that could be detected with the different radioimmunoassays were 20,30 and $10 \mathrm{ng}$, respectively.

To test the specificity of the radioimmunoassays for $\mathrm{CI}$ and $\mathrm{CII}$, bacterial proteins prepared from free-living $R$. leguminosarum were used as a control. No inhibition of binding could be detected with $5 \mathrm{mg}$ bacterial proteins. For both of the leghaemoglobin assays, root proteins from uninoculated plants were used as a control. A maximum of $5 \%$ of the binding could be inhibited by root proteins, and the amounts of leghaemoglobin quantified have been corrected for this factor.

\section{Appearance of leghaemoglobin and nitrogenase}

On pea plants inoculated with $R$. leguminosarum, root nodules were large enough to be picked with forceps about $10 \mathrm{~d}$ after sowing. Pea plants were cultured in such a way that root nodules were preferentially formed on the main root. To extend quantitative measurements of the amounts of CI, CII and leghaemoglobin to plants younger than $10 \mathrm{~d}$, bacteroids and soluble plant proteins were isolated from pieces of the main root where root nodules normally appear. 


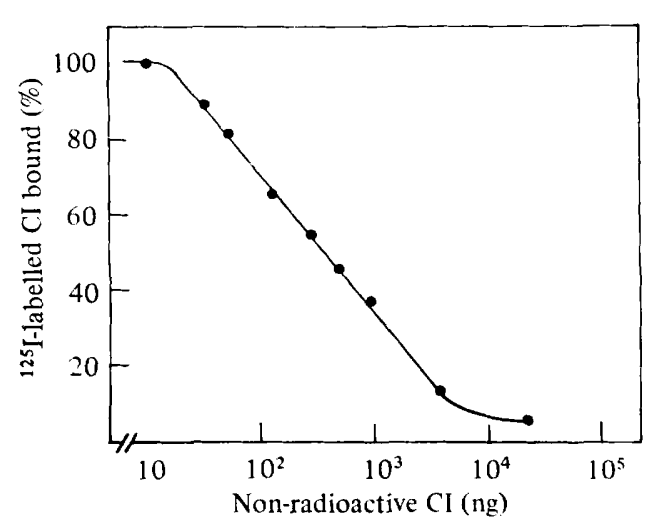

Fig. 1

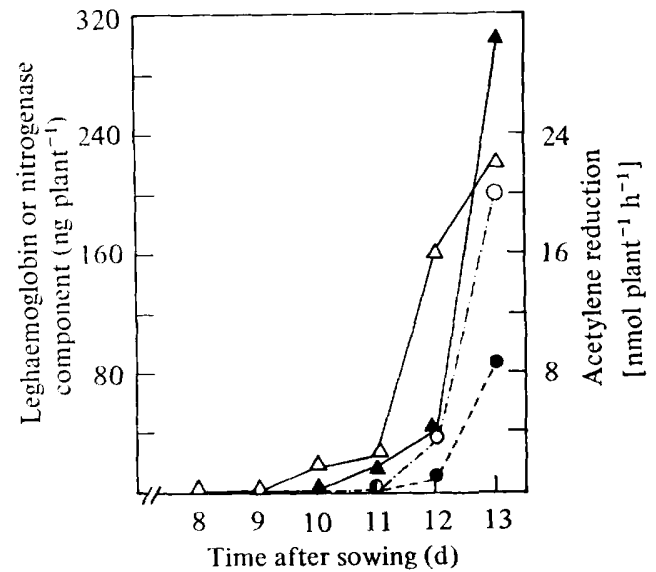

Fig. 2

Fig. 1. Inhibition of binding of ${ }^{125}$ I-labelled CI to anti-CI serum as a function of the amount of non-radioactive CI present.

Fig. 2. Acetylene reduction $(\bigcirc)$, leghaemoglobin $(\Delta)$, component $I(\Delta)$ and component II $(\boldsymbol{O})$ contents during development of the root nodule system of Pisum sativum inoculated with $R$. leguminosarum: 75 plants were used for each estimation.

Table 1. Component I and component II content during development of the root nodule system of $P$. sativum inoculated with $R$. leguminosarum

$\begin{array}{cccc}\begin{array}{c}\text { Time after } \\ \text { sowing (d) }\end{array} & \begin{array}{c}\text { CI } \\ \text { (ng plant }\end{array}{ }^{1} \text { ) } & \begin{array}{c}\text { CII } \\ \text { (ng plant }^{-1} \text { ) }\end{array} & \begin{array}{c}\text { Ratio } \\ \text { CI/CII* }\end{array} \\ 8 & \text { ND } & \text { ND } & - \\ 9 & \text { ND } & \text { ND } & - \\ 10 & 1 \cdot 4 & \text { ND } & - \\ 11 & 20 & 1 \cdot 2 & 17 \\ 12 & 41 & 10 & 4 \cdot 1 \\ 13 & 302 & 83 & 3 \cdot 6\end{array}$

ND, Not detectable.

* Molecular weights of CI and CII are about 200000 and 65000, respectively (Whiting \& Dilworth, 1974). This implies that at a ratio of $3 \cdot 1, \mathrm{CI}$ and $\mathrm{CII}$ are present in equimolar amounts.

Figure 2 shows the amounts of CI, CII and leghaemoglobin, together with the nitrogenase activity, at different times after sowing. At day 10 leghaemoglobin was first detected, while acetylene reduction was not detected until $2 \mathrm{~d}$ later. The separate nitrogenase components appeared immediately after the onset of nodule formation; CI was first detected at day 10 , the same day as leghaemoglobin, while CII was first detected at day 11 . Acetylene reduction became measurable at day 12 (Fig. 2).

At day 11 the ratio of the amounts of CI and CII was 17, while by days 12 and 13 this ratio had rapidly decreased to $4 \cdot 1$ and $3 \cdot 6$, respectively (Table 1). At day 10 , the amount of CII (per 75 plants) was below the limit of detection $(20 \mathrm{ng})$; taking into account the amount of $\mathrm{CI}$ found on this day, this implies that the $\mathrm{CI} / \mathrm{CII}$ ratio was certainly greater than 4 . The results in Table 1 suggest that during root nodule formation the ratio of the amounts of $\mathrm{CI}$ and CII is not constant. Initially CI could easily be detected whereas CII could not, implying that $\mathrm{CI}$ is synthesized before CII.

This experiment was performed three times; in all cases, CI appeared at the same time as leghaemoglobin on day 10, while CII always appeared later. In two experiments, CII was detected at day 12 together with the first acetylene reduction, while in the experiment of Table 1, CII was detected at day 11. In the two experiments when CII could not be detected at day 11 , the bacteroids from 75 plants contained 140 and $200 \mathrm{ng} \mathrm{CI}$. This means that if 


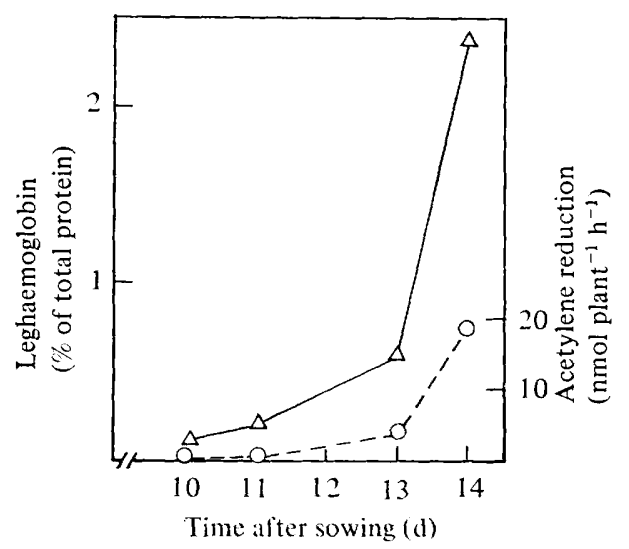

Fig. 3. Acetylene reduction $(O)$ and leghaemoglobin content $(\triangle)$ during development of the root nodule system of Vigna unguiculata inoculated with Rhizobium sp. 32H1: 25 plants were used for each estimation.

the amount of CII present in these bacteroids was below the detection limit of $20 \mathrm{ng}$, the ratios of the amounts of CI and CII were at least 7 and 10.

The appearance of nitrogenase activity and leghaemoglobin was also studied in cowpea plants inoculated with Rhizobium sp. 32H1 (Fig. 3). By $10 \mathrm{~d}$ after sowing, nodule formation was observed; the root nodules were preferentially formed on the main root. At day 10 , leghaemoglobin was detected in these small root nodules by radioimmunoassay. This was followed $1 \mathrm{~d}$ later by the first detection of acetylene reduction. Thus, in this system too, nitrogenase activity was preceded by leghaemoglobin synthesis.

\section{DISCUSSION}

We have suggested earlier that in pea root nodules leghaemoglobin synthesis starts before nitrogenase activity is measurable (Bisseling et al., 1979). This conclusion was based on an extrapolation of results in which leghaemoglobin was first perceptible on the same day as nitrogenase activity. This extrapolation was necessary because of the relative insensitivity of the Mancini immunodiffusion assay as compared to the radioimmunoassay described here, which is a hundred times more sensitive. The results in this paper provide strong evidence that leghaemoglobin is synthesized in root nodules of pea plants before an active nitrogenase complex is detectable. In cowpea root nodules, leghaemoglobin synthesis also preceded acetylene reduction. These results do not prove, but strongly suggest, that leghaemoglobin is essential for nitrogen fixation in legumes in symbiosis with slow-growing as well as fast-growing rhizobia.

That leghaemoglobin synthesis precedes nitrogenase activity is consistent with the results of Godfrey et al. (1975) (R. lupini, leghaemoglobin determined immunologically), Robertson et al. (1975) (R. lupini), Bergersen \& Goodchild (1973) ( $R$. japonicum, assayed by the pyridine haemochrome assay) and Verma (1979) ( $R$. japonicum, assayed by the leghaemoglobincomplementary DNA probe), who all studied slow-growing rhizobia. However, Broughton et al. (1978) (Rhizobium sp., assayed by the Mancini immunodiffusion assay) reported that leghaemoglobin appeared a few days later than nitrogenase activity. The discrepancy between this result and ours may be explained by the relative insensitivity of the Mancini immunodiffusion assay used by Broughton et al. (1978).

We could not detect CI or CII of nitrogenase in proteins prepared from $R$. leguminosarum bacteria cultured in broth. This result is contradictory to experiments described by Bishop et al. (1975), who showed that a protein cross-reacting with anti-CI serum is synthesized 
by broth-cultured bacteria, which do not reduce acetylene. In our opinion, these authors did not rigorously exclude the possibility that a protein other than CI was precipitated, since more than one precipitation band was observed in their immunodiffusion experiments and also a precipitation band could be obtained with protein preparations of $\mathrm{NH}_{4}{ }^{+}$-grown Azotobacter vinelandii.

In pea plants inoculated with $R$. leguminosarum, we found that at the beginning of root nodule formation, $\mathrm{CI}$ is synthesized preferentially. CII could not be detected in young nonnitrogen-fixing root nodules (days 10 and 11), while CI was present and the ratio of the amounts of CI and CII was much higher than in nitrogen-fixing bacteroids (days 12 and 13). This result indicates that $\mathrm{CI}$ is synthesized before $\mathrm{CII}$ and might have some regulatory function, possibly for the complete derepression of the nif genes. It has also been reported that in Clostridium pasteurianum $\mathrm{CI}$ is synthesized before $\mathrm{CII}$ after derepression of the nif genes (Seto \& Mortenson, 1974).

The fact that CI appeared before CII confirms our earlier experiments (Bisseling et al., 1979; van den Bos et al., 1978) in which protein synthesis of bacteroids was studied during nodule development.

We thank Mr Van Geffen, Mr Van Velsen and Mr Houwers for cultivating nodulated pea and cowpea plants, $\mathrm{Mr}$ Hontelez for purifying the nitrogenase components, $\mathrm{Mr}$ Hoogeveen for making the illustrations and Ms Wil Landeweerd for typing. This investigation was partially supported by the Netherlands Foundation for Biological Research (B.I.O.N.) with financial aid from the Netherlands Organization for the Advancement of Pure Research (Z.W.O.).

\section{REFERENCES}

Bergersen, F. J. \& GoOdchild, D. J. (1973). Cellular location and concentration of leghemoglobin in soybean root nodules. Australian Journal of Biological Sciences 26, 741-756.

Bishop, P. E., Evans, H. J., Daniel, R. M. \& HAMPTON, R. O. (1975). Immunological evidence for the capability of free-living Rhizobium japonicum to synthesize a portion of a nitrogenase component. Biochimica et biophysica acta 381, 248-256.

Bisseling, T., van den Bos, R. C. \& van Kammen, A. (1978). The effect of ammonium nitrate on the synthesis of nitrogenase and the concentration of leghaemoglobin in pea root nodules induced by Rhizobium leguminosarum. Biochimica et biophysica acta 539, 1-11.

Bisseling, T., van den Bos, R. C., Weststrate, M. W., HakkaArt, M. J. J. \& van Kammen, A. (1979). Development of the nitrogen-fixing and protein-synthesizing apparatus of bacteroids in pea root nodules. Biochimica et biophysica acta 562, 515-526.

VAN DEN Bos, R. C., Bisseling, T. \& VAN KaMMEN, A. (1978). Analysis of DNA content, nitrogenase activity and in vivo protein synthesis of Rhizobium leguminosarum bacteroids on sucrose gradients. Journal of General Microbiology 109, 131-139.

Broughton, W. J., НоH, C. H., Behm, C. A. \& TUNG, H. F. (1978). Development of the nitrogen fixing apparatus in the legumes Centrosema pubescens Benth. and Vigna unguiculata L. Walp. Planta 139, 183-192.

Godfrey, C. A., Coventry, D. R. \& Dilworth, M. J. (1975). In Nitrogen Fixation by Free-living
Microorganisms, International Biological Programme, vol. 6, pp. 311-332. Edited by W. D. P. Stewart. Cambridge: Cambridge University Press. HunTER, M. W. (1967). In Handbook of Experimental Immunology, vol. 1, pp. 17.1-17.36. Edited by D. M. Weir. Oxford: Blackwell Scientific Publications.

Mancini, O., Carbonara, A. O. \& Heremans, J. F. (1965). Immunochemical quantitation of antigens by single radial immunodiffusion. Immunochemistry 2, 235-254.

PaAu, A. S. (1978). A possible mechanism for the establishment of nitrogen fixation in bacteroids of fast-growing, acid-producing Rhizobium. Journal of Theoretical Biology 74, 139-142.

Robertson, J. G., Farnden, K. J. F., Warburton, M. P. \& Banks, J. M. (1975). Induction of glutamine synthetase during nodule development in lupin. Australian Journal of Plant Physiology 2, 265-272.

Seto, B. \& Mortenson, L. E. (1974). In vivo kinetics of nitrogenase formation in Clostridium pasteurianum. Journal of Bacteriology 120, 822830.

VERMA, D. P. S. (1979). Expression of host genes during symbiotic nitrogen fixation. In Genome Organisation and Expression in Plants, NATO Advanced Studies Institute, FEBS Advanced Course, Edinburgh.

Whiting, M. J. \& Dilworth, M. J. (1974). Legume root nodule nitrogenase purification, properties and studies on its genetic control. Biochimica et biophysica acta 371, 337-351. 